Servicio de publicaciones y difusión científica (SPDC), Universidad de Las Palmas de Gran Canaria, Parque CientíficoTecnológico, Edificio Polivalente II, C/ Practicante Ignacio Rodríguez, s/n Campus Universitario de Tafira 35017 - Las Palmas de Gran Canaria, Spain.

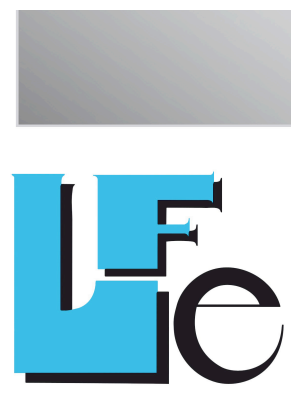

Revista de Lenguas para Fines Específicos

\section{Revista de lenguas} para fines específicos elSSN: 2340-8561

Journal information, indexing and abstracting details, archives, and instructions for submissions: https://ojsspdc.ulpgc.es/ojs/index.php/LFE/index

\section{Exploring acknowledgement practices in English-medium astrophysics research papers: Implications on authorship}

\section{David I. Méndez - M. Ángeles Alcaraz}

Department of Physics, System Engineering and Signal Theory, Polytechnic University College, University of Alicante (Spain).

Article first published online: 27 July 2015.

Article published online with DOI added: 5 April 2016

Revista de Lenguas para fines específicos is licensed under a Creative Commons ReconocimientoNoComercial-SinObraDerivada 4.0 Internacional License. 


\title{
Exploring acknowledgement practices in English- medium astrophysics research papers: Implications on authorship
}

\author{
David I. Méndez ${ }^{1}$
}

Universidad de Alicante

\author{
M. Ángeles Alcaraz \\ Universidad de Alicante
}

\begin{abstract}
This article reports the findings of a diachronic study of acknowledgement practices in 300 randomly collected research papers published during three different periods (1998, 2004 and 2012) in the most prestigious American and European astrophysics journals written in English. In order to investigate the influence of these practices on authorship patterns, we analyzed the distribution over time of a series of quantitative variables (number, length and types of acknowledgements, mean number of words/number of acknowledgements per research paper and mean number of acknowledgements/number of authors per research paper, number of named and unnamed acknowledgees, number of identified and anonymous referees, and number of emotionally charged-words). Comparisons between periods were carried out and Student's t-tests were applied to the quantitative results. Our main findings show that acknowledgements are very common in astrophysics since they are present in $96 \%$ of the whole corpus. Financial, mainly public, and instrumental supports are the most frequently acknowledged categories. The number and length of acknowledgements and the mean number of words/number of acknowledgements per research paper grow over time. Financial, instrumental and conceptual assistance, unnamed individuals and anonymous referees increase over time, whereas moral, editorial and unclassified supports, named individuals and identified referees, and emotionallycharged words decline. If we focus on each journal publication context, we can observe that the research papers published in the American journals include more and longer
\end{abstract}

\footnotetext{
Corresponding author - Department of Physics, System Engineering and Signal Theory, Polytechnic University College, University of Alicante (Spain).

Email: david.mendez@ua.es
} 
acknowledgements, with a higher mean number of acknowledgements per author, more financial and instrumental supports, and a lower percentage of emotionally-charged words, whereas the European journals contain more conceptual and editorial supports. All these data can be understood in the frame of growing scientific professionalism, while a detailed cross-journal analysis may occasionally suggest honorary/guest/gift authorship.

Keywords: astrophysics, research papers, acknowledgements, authorship

\section{RESUMEN}

Este trabajo presenta los resultados de un estudio diacrónico de los agradecimientos en una muestra de 300 artículos de investigación recogidos al azar y publicados durante tres periodos diferentes (1998, 2004 y 2012) en las más prestigiosas revistas de astrofísica, americanas y europeas, escritas en inglés. Con el fin de estudiar la influencia de los agradecimientos sobre los patrones de autoría, hemos analizado la evolución de una serie de variables cuantitativas (número, longitud y tipos de agradecimientos, media del número de palabras/número de agradecimientos por artículo y media del número de agradecimientos/número de autores por artículo, número de personas agradecidas identificadas y no identificadas, número de árbitros mencionados por su nombre y anónimos, y número palabras con carga emocional). Hemos utilizado la prueba t de Student para comparar los resultados cuantitativos entre periodos. Nuestros resultados principales muestran que los agradecimientos son muy comunes en astrofísica ya que están presentes en el $96 \%$ de todo el corpus. Las ayudas económicas, principalmente públicas, instrumentales y conceptuales son las más frecuentes. El número y la longitud de los agradecimientos, así como la media del número de palabras/número de agradecimientos por artículo, crecen paulatinamente. El apoyo económico, instrumental y conceptual, los individuos no identificados y los árbitros anónimos también aumentan, mientras que el apoyo moral, editorial y no clasificado, los individuos y los árbitros identificados, y las palabras con carga emocional decrecen. Si nos centramos en el contexto de cada publicación, observamos que los artículos publicados en las revistas americanas incluyen más agradecimientos y que éstos son más largos, con una media mayor del número de agradecimientos/número de autores, más ayudas económicas e instrumentales, y un menor porcentaje de palabras con carga emocional, en tanto que los artículos publicados en las revistas europeas incluyen más ayudas conceptuales y editoriales. Todos estos datos se pueden entender en el marco de una creciente profesionalización de la ciencia, mientras que un análisis detallado de cada revista puede ocasionalmente sugerir la existencia de una autoría honoraria/invitada/regalada.

Palabras claves: astrofísica, artículo de investigación, agradecimientos, autoría

\section{Introduction and motivation}

The fact that teamwork, a characteristic feature of "Big Science" (Weinberg, 1961, 1968; de Solla Price, 1963) which relies on large-scale, big-budgeted, and hierarchically-organized projects funded by national governments or groups of governments (Galison, 1992), usually prevails nowadays, implies that research "is produced by and in a network of actors" (Shapin, 1995, p. 
359). The network not only involves the work of primary author(s), but also of secondary author(s), or sub-authors (Patel, 1973; Cronin et al., 2003), whose contribution to a study was not significant enough to qualify them as author(s) (Rennie et al., 1997; Kassirer \& Angell, 1991; Claxton, 2005; Slatcher \& Pennebaker, 2006). It is therefore very common to find a section in academic and scientific articles where the authors express their thanks and gratitude to the diverse individuals (and/or entities) that have contributed, funded, supported, or discussed their work (Gesuato, 2004; Giles \& Councill, 2004; Khabsa et al., 2012). In other words, acknowledgements (ACKs) demonstrate how new research is embedded within the different disciplinary communities and reveal like no other academic texts the intricate webs of interpersonal debts produced in the dialogic process of knowledge construction, where the expression of scholarly gratitude counts as a form of repayment for balancing such debts (Swales, 2004). A good index of the importance attributed to ACKs in today's scholarly communication is the proportion of studies that have been devoted to their analysis by scholars from a variety of different disciplines, genres and standpoints (for a comprehensive bibliographic review see Hyland, 2004 and Salager-Meyer et al., 2009, 2011 among others).

Moreover, when research is carried out by very heterogeneous groups of scientists, "deciding who should or should not be an author or acknowledged can be a controversial issue" (Hare, 2001, p. 249), as has been put forward in many studies, especially in medical sciences (Gasparyan et al., 2013; Vinther \& Rosenberg, 2012, to name just a few). The multifaceted authorship problems in scholarly journals have given way to a range of inappropriate practices which include ghost, honorary, guest, and gift authorship. 'Ghost' authorship refers to scientists who are not listed as authors in spite of their substantial contributions to research. Conversely, 'honorary' authorship refers to authors who did not significantly contribute to the research but only provided facilities or technical support. 'Guest' authorship refers to listing as co-authors very well-known scientists who have had little to do with the work involved, with a hope to increase publication chances and career prestige. Finally, 'gift' authorship takes places when a colleague's name is added for encouraging collaboration, maintaining good working relations, attempting to boost his/her profile or as repayment for favours. The nonadherence to appropriate authorship criteria may give rise to significant variations in ACK-patterns. Within this changing scenario, the analysis of emotionally-charged words (Giannoni, 2006; Salager-Meyer et al., 2009) may play a key role in understanding the practices in context. 
In spite of the vast and heterogeneously rich literature on ACKs, there is a discipline where they have seldom been the object of study: astrophysics. It is a global and multidisciplinary science which combines astronomy, an observational science related to the description and the classification of the universe, and physics, which is concerned with the basic properties of celestial objects (Pedersen, 2009). Moreover, physics not only incorporates theory and practice (Newman, 2004), but also separate branches of fields of expertise, each one with its own characteristics: high-energy physics, particle physics, relativistic physics, solid-state physics, mathematics, chemistry, biology, mechanical/electrical/aerospace engineering, etc.

As far as we know, there is only an Astronomy Acknowledgment Index (AAI), compiled by Verner (1992, 1993, 1996), that lists personal ACKs included in papers published in the leading journals in astronomy. Indeed, the field of physics has been addressed in only a few occasions from linguistic, rhetoric, pragmatic, and/or bibliometric points of view. For instance, Suls \& Fletcher (1983) performed a comparative study of ACKs between social and physical sciences; Hyland (1998) analysed metadiscourse in four academic disciplines (applied linguistics, astrophysics, marketing and microbiology); Tarone et al. (1998) conducted research on the use of the passive voice in astrophysics research articles; Bazerman (2000) devoted the third part of his volume Shaping written knowledge: The genre and activity of the experimental article in science to the changing forms of the experimental report within twentiethcentury physics and the individual's activity in writing and reading texts; Butler Burton (2007) examined the growth of scientific authorship in the most prestigious astrophysics journals; Gentil-Beccot et al. (2009) approached the issue of citing and reading behaviours in high-energy physics papers; Costas \& Leewen (2012) examined ACKs across different countries and disciplines, among them physics and astronomy; and Méndez et al. (2014a, 2014b) carried out a diachronic analysis of titling and authorship in astrophysics research papers (RPs) written in English.

It is thus our intention here to extend the line of research on astrophysics in general and on ACKs in particular by presenting the results of an empirical study of ACKs drawn from a corpus of 300 randomly collected RPs in astrophysics published between 1998 and 2012 in English-written journals (see 'Corpus' below). Since the present study completes our previous research on authorship (Méndez et al., 2014b), we expect to provide a full picture of the construction of scientific knowledge and scholarly production in the field of astrophysics. 
The present study then deals with the evolution of ACKs regarding their number, length, and types. Other questions related to the distribution over time of named and unnamed individuals, identified and anonymous referees, as well as the presence and evolution of emotionally charged-words, are also addressed in this research. More precisely, this study aims at answering the following main questions:

1. Are there any time variations in the frequency, length and types of ACKs?

2. Does the relationship between the number of ACKs and the number of author(s) per RP vary over time?

3. Does the frequency of acknowledging named and unnamed individuals, and identified and anonymous referees change over time?

4. Does the distribution of the variables above depend upon a journal's scope or its geographic orientation?

5. Does the use of emotionally-charged word change over time?

\section{Corpus and methodology}

In studies of this kind, it is recommended to draw the sample texts in topranking journals because, as Connor (2004) argues, the articles published in these journals have undergone a strict peer review and editorial scrutiny. Such a procedure thus assures that the articles selected are fairly representative of the journal genre in content and style or, in Bazerman's words (1994, p. 23), that the texts are "situationally effective" and are the results of an "expert performance" (Bazerman, 1994, p. 131). Following then Connor (2004)'s recommendation, our journal selection incorporated the following criteria:

1. Represent the best practices in the field;

2. Publish papers on observational data and/or theoretical analyses;

3. Be freely accessible online.

Four journals were found to meet the three criteria and were selected for this study: two European journals [Astronomy and Astrophysics (A\&A), Monthly Notices of the Royal Astronomical Society (MNRAS)] and two US-based journals [The Astronomical Journal (AJ), and The Astrophysical Journal (ApJ)²]. Since 1998

2 The Impact Factors listed in the journal home page refer to the year 2012 (A\&A 5.084, AJ 4.965, ApJ 6.733, and MNRAS 5.521). 
was the initial free online access date shared by the four journals, we chose that year as the starting point of our research.

It is important to mention here that the guidelines of the journals selected in this study do not specifically require but only recommend an ACK-section to be included. For example, ApJ and AJ quote that "At the end of the paper individuals, institutions, or funding agencies may be acknowledged", whereas $A \& A$ mentions that "A special section for acknowledgements may be included before the References list", and MNRAS reads that "Conclusions should be followed by un-numbered acknowledgements." In this sense, it could be stated that acknowledging any kind of help for the conduction of studies is not mandatory in these four astrophysical journals although, as it will be seen later on, the vast majority of the RPs included in our sample contain a section devoted to ACKs.

The best option to answer questions 1), 2), 3), and 4) formulated in the "Introduction" section is evidently the analysis of different time periods, journals and contexts. This is the reason why we randomly collected 300 RPs from three different time periods comprising 100 RPs each: Block A (1998), Block B (2004), and Block C (2012). In other words, the 100 RPs per Block comprise 25 RPs per journal, i.e. a total of 75 RPs per journal. Then we manually counted the number of RPs with ACKs, the number of ACKs and the words making up the ACK-sections. The concept of "word" was defined as the unit occurring between spaces.

Since ACKs embody different relationships among people, agencies, and institutions, we followed a classifying typology similar to that already used by Cronin (1995), Hyland (2003), Giles \& Councill (2004), and Salager-Meyer et al. (2009):

1. Financial support, i.e., recognition of external and/or intra-mural funding of national and/or international private and/or public educational institutions, federal/governmental research agencies and/or industrial sources/sponsors.

2. Instrumental/technical support, e.g., providing access to tools, facilities, technologies and infrastructural resource; furnishing technical expertise, help in data collection/entry/management.

3. Conceptual support, also called "academic support" (Hyland, 2003, p. 244) or "peer-interactive communication (PIC)" (McCain, 1991, p. 512), such as proffering thanks for advice and discussion, comments on the manuscript, critical insight, intellectual guidance, valuable suggestions, assessment on study soundness, etc.

4. Moral support: e.g. thanking someone for his/her enthusiasm, encouragement, wisdom. 
5. Editorial/linguistic support, i.e., editing, proofreading or translating the manuscript.

6. Unclassifiable when it proved impossible to categorize an ACK according to any of the above categories whether because of inherent ambiguity, vagueness or lack of contextual clues.

We also recorded the number of named and unnamed individuals acknowledged. In the case of named individuals, they were identified either by their full name and surname or by their initial name and full surname, whereas the label "unnamed individuals" was applied to individuals and groups of people whose help in the research and/or comments/suggestions, etc. was acknowledged (staff, teams, colleagues, research centres, scientists, investigators, project and department directors, technicians, editor(s), referee(s), etc.). Finally, for our linguistic analysis and in order to answer question 5), we also registered all the emotionally-charged words included in our corpus in order to check if there were any diachronic differences across the four journals.

In the case of the quantitative/numerical variables, to assess whether some of the paired two-sample differences observed were statistically significant or not, we analysed our results by means of the Student's $t$-test. The alpha value was set at 0.05 .

\section{Results}

\subsection{ACK-practices}

As can be seen in Table 1 below, 96\% of the 300 analysed RPs contain ACKs. Table 1 also shows that the greatest number of ACKs and of words making up the ACK-sections was recorded in AJ. The highest mean number of words/number of ACKs per RP and number of words/number of authors per RP was also found in AJ.

Statistically significant differences were found in the mean number of words/number of ACKs per RP $(p=0.0016)$ and in the mean number of ACKs/number of authors per RP $(p=0.011)$ between AJ and A\&A. Statistically significant differences $(p=0.025)$ were also appreciated in the mean number of words/number of ACKs per RP between MNRAS and A\&A grouped together (14.0) and between $A J$ and ApJ grouped together (16.1). Further statistically significant differences $(p=0.038)$ were also found in the mean 
number of ACKs/number of authors per RP between MNRAS and A\&A grouped together (1.7) and AJ and ApJ also grouped together (2.0).

\begin{tabular}{|c|c|c|c|c|c|}
\hline Journals & AJ & MNRAS & ApJ & A\&A & Total \\
\hline No. of RPs with ACKs & 74 & 73 & 71 & 70 & 288 \\
\hline No. of ACKs & 461 & 405 & 393 & 367 & 1626 \\
\hline No. of ACK-words (ACK-length) & 7223 & 6007 & 6024 & 5084 & 24338 \\
\hline $\begin{array}{l}\text { Mean no. of words/no. of } \\
\text { ACKs per RP }\end{array}$ & 16.6 & 14.5 & 15.7 & 13.5 & 15.0 \\
\hline $\begin{array}{l}\text { Mean no. of ACKs/no. of } \\
\text { authors per RP }\end{array}$ & 2.1 & 1.8 & 1.9 & 1.5 & 1.8 \\
\hline
\end{tabular}

Table 1. Number of RPS with ACKs and of $A C K S^{3}$, number of $A C K$-words, mean number of words/number of $A C K s$ per $R P$, and mean number of $A C K s /$ number of authors ${ }^{4}$ per RP

Diachronically speaking, Table 2 shows that the number of RPs with ACKs is the same in each of the three blocks. The total number of ACKs and of ACKwords rises steadily from Block $A$ to Block $C$, mainly from Block $B$ to Block $C$ where the increase is quite sharp.

\begin{tabular}{l|c|c|c|c}
\hline Periods & Block A & Block B & Block C & Total \\
\hline No. of RPs with ACKs & 96 & 96 & 96 & 288 \\
\hline No. of ACKs & 512 & 510 & 604 & 1626 \\
\hline No. of ACK-words (ACK-length) & 7130 & 7348 & 9860 & 24338 \\
\hline Mean no. of words/no. of ACKs per RP & 13.5 & 14.5 & 17.2 & 15.0 \\
\hline Mean no. of ACKs/no. of authors per RP & 2.0 & 1.7 & 1.7 & 1.8 \\
\hline
\end{tabular}

Table 2. Evolution of the number of RPs with ACKS, of ACKs, of ACK-words, and of the mean number of words/number of ACKS per RP and number of ACKs/number of authors per RP

The mean number of words/number of ACKs per RP shows a statistically significant increase from Block $A$ to Block $C(p=0.007)$, whereas the decrease in the mean number of ACKs/number of authors per RP for the same time band is not statistically significant.

The total number of ACKs exceeds 75 (the number of articles sampled from each journal) because authors usually make acknowledgements for multiple reasons, such as external funding, conceptual, and technical/instrumental/moral support.

$4 \quad$ These data have been calculated by taking into account the number of authors (per journal and period) reported by Méndez et al. (2014b) in their study with the same corpus. 
The evolution of the mean number of words/number of ACKs per RP per journal is plotted in Figure 1.

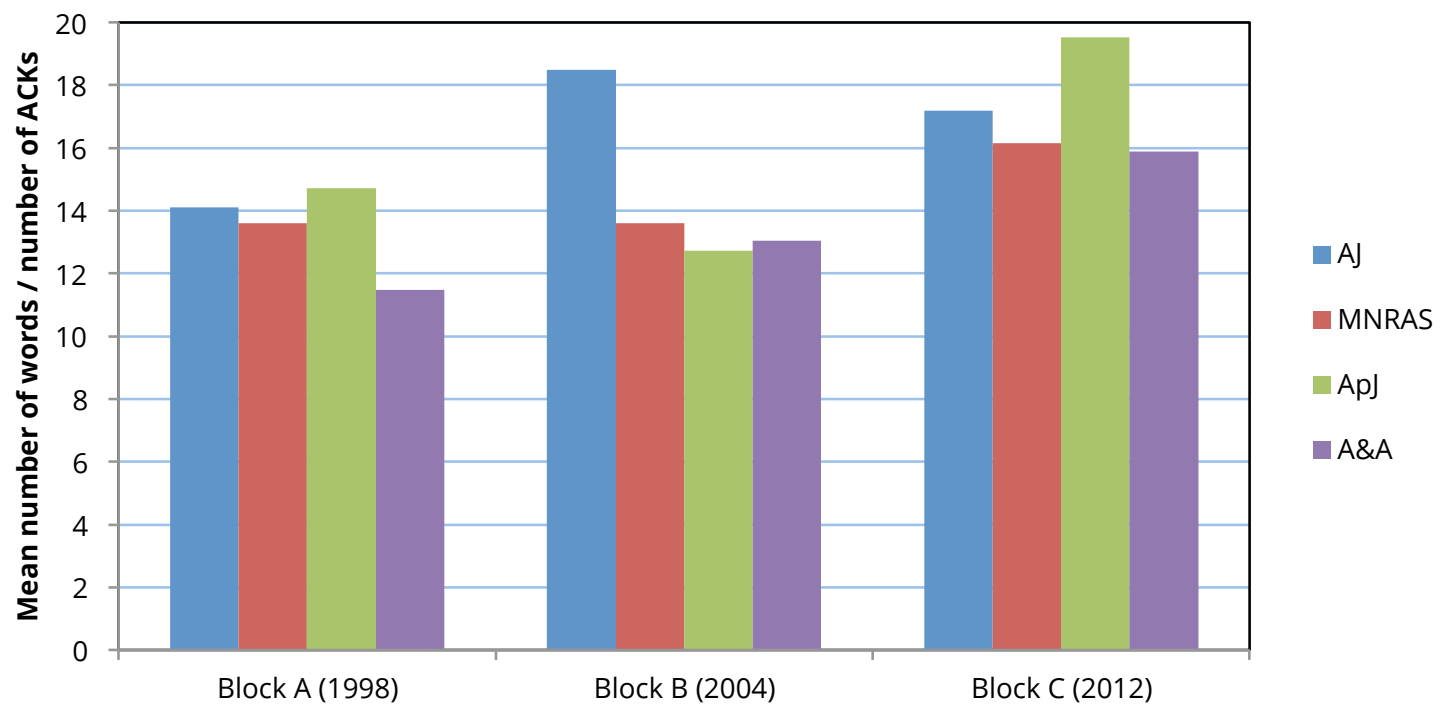

Figure 1. Evolution of number of words/number of ACKs per RP per journal.

The overall increase in the mean number of words/number of ACKs per RP from Block A (14.1) to Block $C(17.2)$ is statistically significant ( $p=0.047)$. In $A$, the mean number of words/number of ACKs per RP rises in Block $B$ (from 14.1 to $18.5, p=0.011$ ) and falls in Block $C$, although with no statistically significant difference. The mean number of words/number of ACKs per RP grows steadily from Block $A$ to Block $C$ in MNRAS (from 13.6 to 16.1, $p=0.036$ ) and in $A \& A$ (from 11.5 to 15.9, $p=0.015$ ). In $A p J$, the mean number of words/number of ACKs per RP shows the opposite behaviour when compared to AJ but with no statistical significance.

The distribution over time of the mean number of ACKs/number of authors per RP per journal is displayed in Figure 2. 


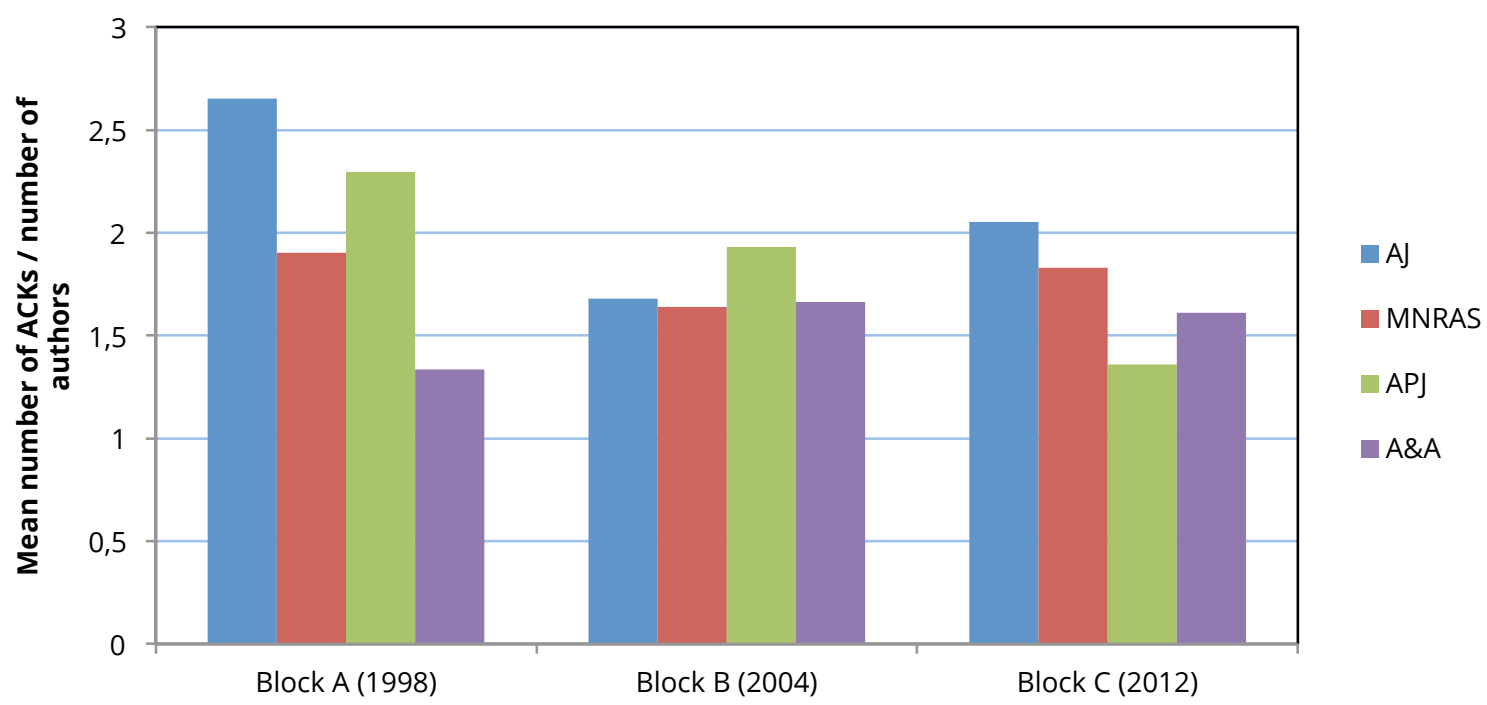

Figure 2. Evolution of the mean number of ACKs/number of authors per RP per journal.

In ApJ, the mean number of ACKs/number of authors per RP falls steadily from 2.2 in Block $A$ to 1.3 in Block $C(p=0.050)$. The mean number of ACKs/number of authors per RP also falls in AJ from 2.7 in Block $A$ to 1.7 in Block $B(p=0.050)$ and rises in Block $C$ although the difference is not statistically significant. If AJ and ApJ are grouped together, there is a steady decrease from Block $A$ (2.5) to Block C (1.7) with even higher statistical significance $(p=0.028)$. On the other hand, MNRAS and A\&A show opposite evolution patterns between them but with no statistical significance.

\subsection{ACK-types}

Table 3 shows that financial (40.40\%), instrumental (30.87\%) and conceptual (22.69\%) ACKs top the list of ACK-types.

\begin{tabular}{l|c|c|c|c|c}
\hline ACK-type & AJ & MNRAS & ApJ & A\&A & Total \\
\hline Financial & 186 & 161 & 170 & 140 & 657 \\
\hline Instrumental & 174 & 114 & 111 & 103 & 502 \\
\hline Conceptual & 80 & 106 & 87 & 96 & 369 \\
\hline Moral & 10 & 11 & 16 & 14 & 51 \\
\hline Editorial & 6 & 7 & 6 & 12 & 31 \\
\hline Unclassifiable & 5 & 6 & 3 & 2 & 16 \\
\hline Total & 461 & 405 & 393 & 367 & 1626 \\
\hline
\end{tabular}

Table 3. ACK-types per journal. 
The greatest number of ACKs (28.35\%) is found in $\mathrm{AJ}$ and the lowest one in A\&A (22.57\%). AJ has also the highest number of financial (28.31\%) and instrumental (34.66\%) ACKs, and the smallest number of conceptual (21.68\%) and moral (19.61\%) ones. Conceptual (28.73\%) and moral (31.37\%) ACKs are prevalent in MNRAS and ApJ, respectively. Editorial ACKs (38.71\%) are predominant in A\&A. Unclassifiable ACKs are present in the four journals.

From a diachronic standpoint, Figure 3 shows an upswing in the number of financial assistance from Block A to Block C. Conversely, editorial, moral and unclassifiable assistance fall steadily (the unclassifiable type is almost absent in Block C), whereas instrumental ACKs decrease in Block B and increase in Block $\mathrm{C}$ and the opposite pattern is observed in conceptual ACKs.

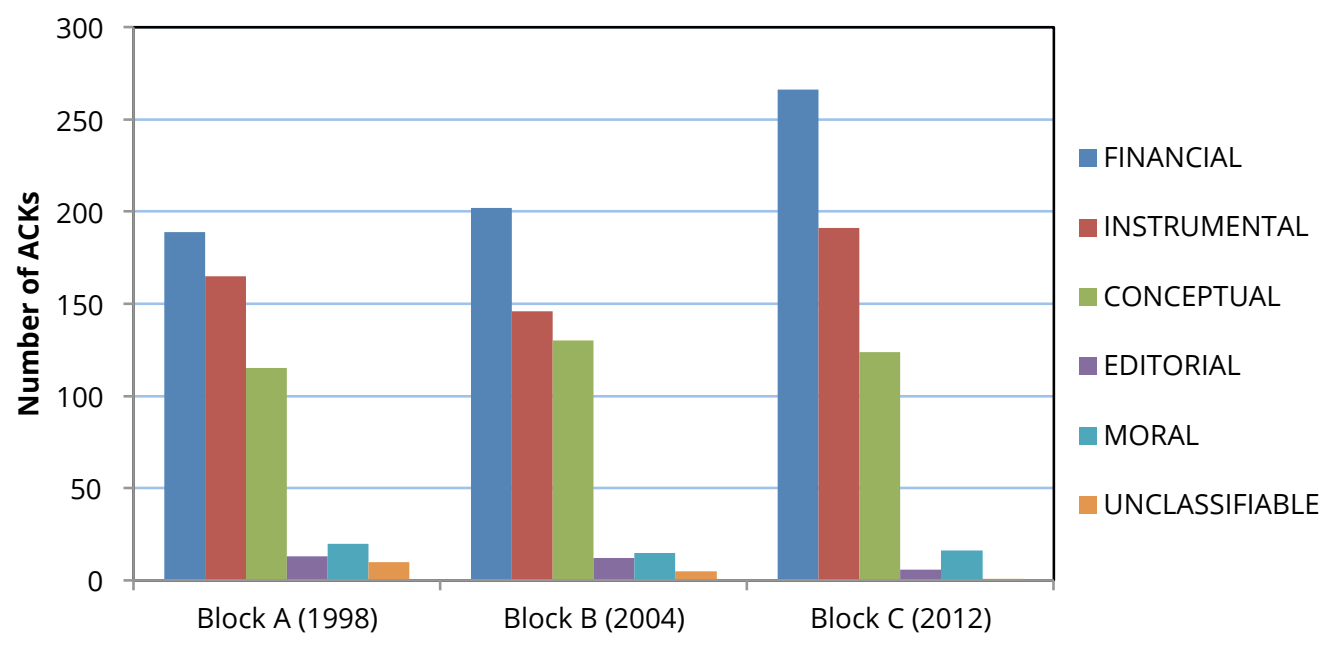

Figure 3. Evolution of ACK-types.

As can be seen in Table 4, financial ACKs rise steadily from Block A (28.77\%) to Block C (40.49\%). However, two discrepancies may be observed between AJ and the other journals: on the one hand, AJ has the highest percentage of financial ACKs (28.31\%) and, on the other, their evolution shows an erratic pattern, whereas in MNRAS, ApJ and A\&A, financial support increases from Block A to Block C.

\begin{tabular}{l|c|c|c|c}
\hline Financial & Block A & Block B & Block C & Total \\
\hline AJ & 63 & 56 & 67 & 186 \\
\hline MNRAS & 39 & 43 & 79 & 161 \\
\hline ApJ & 49 & 58 & 63 & 170 \\
\hline A\&A & 38 & 45 & 57 & 140 \\
\hline Total & 189 & 202 & 266 & 657 \\
\hline
\end{tabular}

Table 4. Evolution of financial ACKs per journal. 
As an aside, it is worth adding that $95.43 \%$ of financial assistance proceeds from public sources against only $4.57 \%$ from private ones.

Table 5 shows that along the same line as financial ACKs, instrumental ACKs increase from Block A (32.87\%) to Block C (38.05\%). Once more, AJ has the highest percentage of instrumental ACKs (34.66\%) and their evolution over time also differs from the remaining journals.

\begin{tabular}{l|c|c|c|c}
\hline Instrumental & Block A & Block B & Block C & Total \\
\hline AJ & 52 & 65 & 57 & 174 \\
\hline MNRAS & 34 & 29 & 51 & 114 \\
\hline ApJ & 42 & 29 & 40 & 111 \\
\hline A\&A & 37 & 23 & 43 & 103 \\
\hline Total & 165 & 146 & 191 & 502 \\
\hline
\end{tabular}

Table 5. Evolution of instrumental ACKs per journal.

Like financial and instrumental ACKs, conceptual ACKs (Table 6) also rise from Block A (31.16\%) to Block C (33.60\%). However, the highest percentage of this ACK-category is found in MNRAS (28.73\%) and not in AJ which, in addition, shows the lowest one (21.68\%). The evolution pattern of conceptual support also varies from one journal to the other.

\begin{tabular}{l|c|c|c|c}
\hline Conceptual & Block A & Block B & Block C & Total \\
\hline AJ & 22 & 34 & 24 & 80 \\
\hline MNRAS & 30 & 29 & 47 & 106 \\
\hline ApJ & 32 & 31 & 24 & 87 \\
\hline A\&A & 31 & 36 & 29 & 96 \\
\hline Total & 115 & 130 & 124 & 369 \\
\hline
\end{tabular}

Table 6. Evolution of conceptual ACKs per journal.

The evolution of moral, editorial, and unclassifiable ACKs per journal is shown in Table 7, below. Unlike financial, instrumental and conceptual support, moral ACKs fall from Block A (39.21\%) to Block C (31.37\%). In this case, the highest percentage of moral ACKs is found in ApJ (31.37\%). As for their distribution over time, AJ distinguishes itself once more from the remaining journals.

Like conceptual ACKs, editorial support decreases from Block A (41.93\%) to Block C (19.35\%). The greatest number of editorial ACKs is found in A\&A (38.71\%). As for unclassifiable ACKs, they decrease steadily from Block $A$ (62.50\%) to Block C (6.25\%). The greatest number of this type of ACK is found in MNRAS (37.50\%), and AJ is the only journal that includes them in Block C. 


\begin{tabular}{l|c|c|c|c}
\hline $\begin{array}{l}\text { Moral / Editorial / } \\
\text { Unclassifiable }\end{array}$ & Block A (1998) & $\begin{array}{c}\text { Block B } \\
\text { (2004) }\end{array}$ & Block C (2012) & Total \\
\hline $\mathrm{AJ}$ & $3 / 2 / 1$ & $3 / 1 / 3$ & $4 / 3 / 1$ & $10 / 6 / 5$ \\
\hline $\mathrm{MNRAS}$ & $4 / 3 / 6$ & $5 / 4 / 0$ & $2 / 0 / 0$ & $11 / 7 / 6$ \\
\hline $\mathrm{ApJ}$ & $7 / 1 / 1$ & $3 / 3 / 2$ & $6 / 2 / 0$ & $16 / 6 / 3$ \\
\hline $\mathrm{A \& A}$ & $6 / 7 / 2$ & $4 / 4 / 0$ & $4 / 1 / 0$ & $14 / 12 / 2$ \\
\hline Total & $20 / 13 / 10$ & $15 / 12 / 5$ & $16 / 6 / 1$ & $51 / 31 / 16$ \\
\hline
\end{tabular}

Table 7. Evolution of moral, editorial, and unclassifiable ACKs per journal.

\subsection{Named and unnamed individuals}

As can be seen in Table 8 , the percentage of named individuals decreases steadily from Block A (38.71\%) to Block C (28.44\%). MNRAS (26.83\%) and ApJ (26.10\%) are the two journals with the greatest percentages of acknowledged individuals mentioned by their names. While the number of named individuals shows a similar behaviour in AJ and ApJ, MNRAS and A\&A display an erratic pattern: in MNRAS the number of credited individuals decreases in Block $B$ and increases in Block $C$, and in A\&A it rises in Block B and falls in Block C.

\begin{tabular}{l|c|c|c|c}
\hline $\begin{array}{l}\text { Named/unnamed } \\
\text { individuals }\end{array}$ & Block A & Block B & Block C & Total \\
\hline AJ & $63 / 13$ & $51 / 10$ & $44 / 12$ & $158 / 35$ \\
\hline MNRAS & $60 / 7$ & $58 / 5$ & $65 / 5$ & $183 / 17$ \\
\hline ApJ & $85 / 10$ & $53 / 5$ & $40 / 12$ & $178 / 27$ \\
\hline A\&A & $56 / 2$ & $62 / 3$ & $45 / 5$ & $163 / 10$ \\
\hline Total & $264 / 32$ & $224 / 23$ & $194 / 34$ & $682 / 89$ \\
\hline
\end{tabular}

Table 8. Evolution of named and unnamed individuals per journal.

Contrary to named individuals, unnamed individuals increase slightly from Block A (35.95\%) to Block C (38.20\%). The highest percentage of unnamed individuals is found in $\mathrm{AJ}(39.32 \%)$ and the lowest one in A\&A (11.23\%). Their evolution pattern also varies. What is more important, though, is that when named and unnamed individuals are grouped together, there is a considerable difference between the former (88.46\%) and the latter (11.54\%).

\subsection{Identified and non-identified referees}

Table 9 shows that identified referees fall from Block A (36.36\%) to Block C (21.21\%), whereas non-identified referees behave the other way round, i.e. they rise steadily from Block A (24.47\%) to Block C (45.74\%). Moreover, non- 
identified referees (74.02\%) amount nearly three times as much as identified ones (25.98\%).

\begin{tabular}{l|c|c|c|c}
\hline $\begin{array}{l}\text { Identified / non- } \\
\text { identified referees }\end{array}$ & Block A & Block B & Block C & Total \\
\hline A & $2 / 5$ & $5 / 8$ & $0 / 13$ & $7 / 26$ \\
\hline MNRAS & $3 / 8$ & $3 / 6$ & $6 / 10$ & $12 / 24$ \\
\hline ApJ & $3 / 3$ & $1 / 9$ & $1 / 8$ & $5 / 20$ \\
\hline A\&A & $4 / 7$ & $5 / 5$ & $0 / 12$ & $9 / 24$ \\
\hline Total & $12 / 23$ & $14 / 28$ & $7 / 43$ & $33 / 94$ \\
\hline
\end{tabular}

Table 9. Evolution of identified and non-identified referees per journal.

\subsection{Linguistic aspects}

Apart from expressing their ACKs by means of verbs such as "acknowledge", "thank", "supported", etc., on some occasions acknowledgers use different emotionally-charged words which usually consist of laudatory adjectives, adverbs and nouns (all of them are listed in the enclosed appendix).

Laudatory adjectives top the list of emotionally-charged words (24 variants are mentioned on 377 occasions), whereas laudatory adverbs (12 variants) appear on 73 occasions and laudatory nouns (two variants) are mentioned on 15 occasions. The ceremonious adjectives mostly used are the predicate "grateful" (89 occurrences) after the verb "to be" and the attributive adjective "useful" (80 occurrences) before nouns such as "comments", "suggestions", etc. The attributive "helpful" appears in mid-position (66 occurrences) and the rest of attributive adjectives run from 18 occurrences ("careful") to the onetime occurrence of "encouraging" and "positive". The laudatory adverb mostly used is "gratefully" (19 occurrences), followed by "greatly" (13 occurrences), whereas "cheerfully", "deeply" and "extremely" appear only once. As for laudatory nouns, the two variants are "gratitude" and "pleasure", both with a similar frequency of appearance (seven and eight occurrences, respectively). The distribution per block and journal of the emotionally-charged words is displayed in Table 10, below.

As table 10 shows, the behaviour of the number of emotionally-charged words is not homogenous: it rises steadily in AJ, falls continuously in ApJ and $A \& A$, and shows an up and down trend in MNRAS. Apart from including more variants, the ACKs in the European journals also contain more ceremonious words (53.33\%) than those in the American ones (47.67\%). 


\begin{tabular}{l|c|c|c|c|c}
\hline $\begin{array}{l}\text { Emotionally- } \\
\text { charged words }\end{array}$ & Variants & Block A & Block B & Block C & Total \\
\hline AJ & 23 & 28 & 38 & 46 & 112 \\
\hline MNRAS & 30 & 41 & 44 & 38 & 123 \\
\hline ApJ & 23 & 42 & 35 & 28 & 105 \\
\hline A\&A & 27 & 53 & 43 & 29 & 125 \\
\hline Total & 38 & 165 & 160 & 140 & 465 \\
\hline
\end{tabular}

Table 10. Evolution of the variants and number of emotionally-charged words per journal.

Figure 4 plots the distribution per block and journal of the percentage of emotionally-charged words in relation to the total length of ACKs. On the one hand, it can be observed that the peak of laudatory words is found in Block $A$ in $A \& A$ and, on the other, that their number decreases from Block $A$ to Block $C$ in MNRAS, ApJ and A\&A, whereas it increases in $A J$ in the same time span. Ceremonious words peak in 1998 in A\&A and decrease from 1998 to 2004 in MNRAS, ApJ, and A\&A. However, they increase over the three sample periods in AJ.

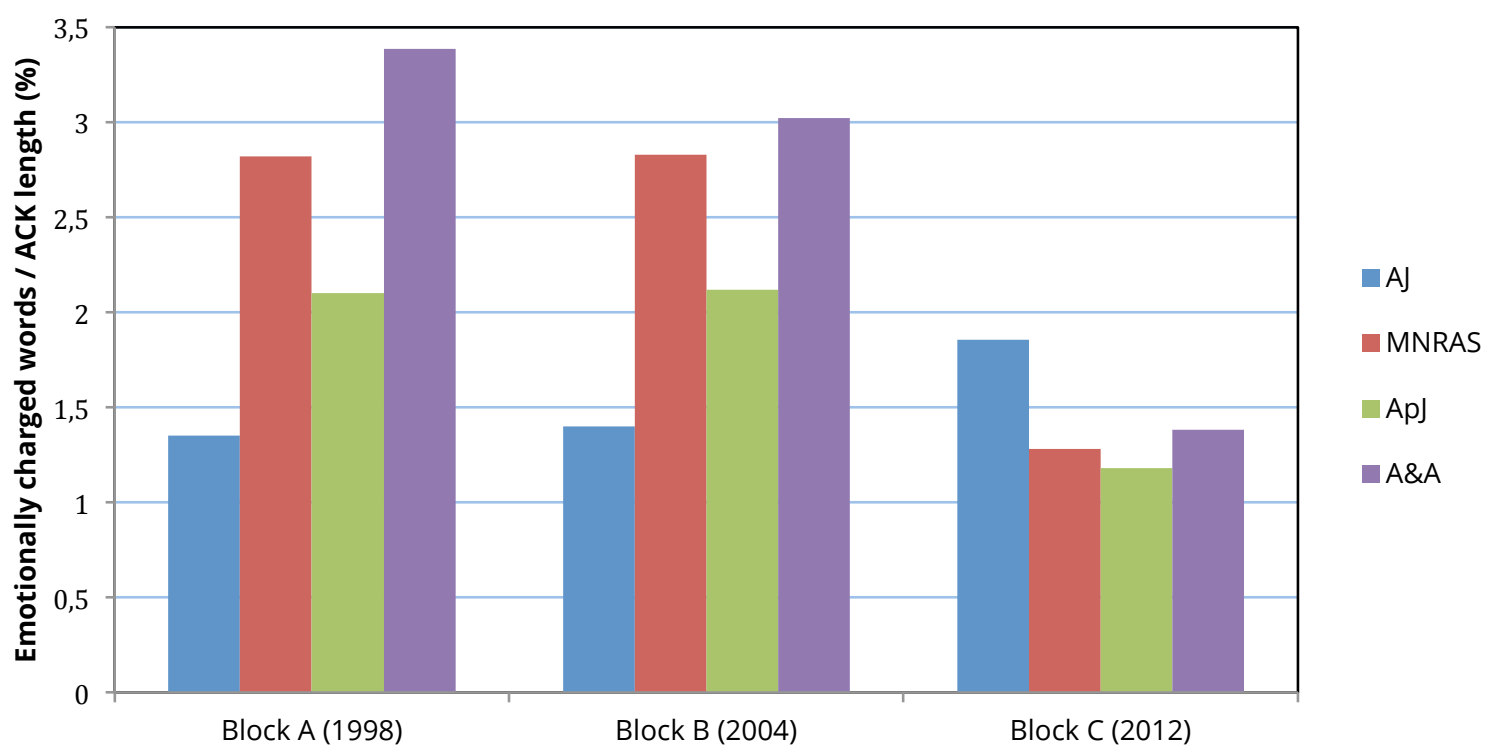

Figure 4. Evolution of emotionally-charged words (percentages) per journal.

Emotionally-charged words decrease in the two European journals grouped together (from 3.08\% in Block A to 1.32\% in Block C), whereas they increase in both American journals grouped together in the same time span (from $1.13 \%$ to $1.54 \%)$. 
Laudatory adjectives are sometimes reinforced by boosters. Of the six variants encountered (see appendix), the highest frequencies of appearance correspond to the quantifier "many" (24 occurrences) and to the adverbial intensifier "very" (19 occurrences). Similarly to emotionally-charged words, there are more boosters and variants in the European journals (62.50\%) than in the American ones (37.50\%).

\section{Discussion}

The data displayed in our tables and figures reveal that ACK-patterns vary over time and per journal. Since the observed variations likely depend upon the scope of each journal and its publication context, the best option to discuss our most relevant findings is to start focusing on each journal individually, then follow with a summary of the main results and finally introduce a distinction between the American and European contexts.

In ApJ, a journal with a general publishing trend which includes experimental and theoretical results, the average ACK-length increases from Block $A$ to Block C (Figure 1) and so does the number of financial ACKs (Table 4), whereas the number of conceptual ACKs decreases (Table 6). Instrumental, moral, editorial and unclassifiable ACKs do not show a great overall variation over time (Tables 5 and 7). The number of named individuals and of identified referees falls over time, whereas the number of unnamed individuals and anonymous referees shows an overall rise (Tables 8 and 9). All these data, as well as the significant overall decline in the mean number of ACKs/number of authors per RP (Figure 2) and the increase in the number of authors in Block C in comparison to Block A (see Méndez et al., 2014b), can be explained in terms of the universal tendencies of globalization, the birth and development of Big Science, and the growing specialization and professionalization of science (Beer \& Lewis, 1963; Gordon, 1980).

In addition, since financial ACKs are the only ACK-types that show a significant rise, we could speculate that some sub-authors, who were previously included in the ACK-sections in Block A and whose contributions to the RP used to be ceremoniously acknowledged, are now appearing as authors (Butler Burton, 2007), although they are only contributing with the mention of their research projects. In this sense, these individuals may be qualified as 'honorary authors' as they did not contribute substantially to be able to take public responsibility for the work. The decrease in the percentage of emotionally-charged words (Figure 4) may also reinforce the afore-mentioned idea, i.e. the previous addressees of laudatory words have 
now turned into authors. Moreover, the Impact Factor of ApJ, indeed the journal with the highest one in our sample, would likewise encourage scientists to be willing to guest/gift authorship in order to increase the chances of publication of their papers or boost their careers (Curry \& Lillis, 2004; Gómez et al., 2006; De Faoite, 2010).

AJ, a journal that focuses primarily on observational research (the most experimental part of astrophysics) which requires complex instrumentation (telescopes, detection devices, space missions, etc.) and multidisciplinary teams, has the greatest number of ACKs and of ACK-words (Table 1), mainly due to the huge presence of instrumental ACKs when compared to the other three journals (Table 3). Likewise, it has the highest mean number of words/number of ACKs per RP and of ACKs/number of authors per RP (Table 1, Figures 1 and 2). Furthermore, AJ shows a significant increase in the mean ACK-length from Block A to Block B (Figure 1) together with an also significant decline in the number of ACKs/number of authors per RP in the same time band (Figure 2), which may be explained in terms of the enormous rise in the number of authors in Block B (see Méndez et al., 2014b). The increase noticed in the number of authors in Block $B$ runs parallel with a rise in the number of instrumental and conceptual ACKs (Tables 5 and 6), whereas financial ACKs (Table 4) decline. The number of named and unnamed individuals falls over time, whereas the number of identified and anonymous referees shows an overall increase (Tables 8 and 9).

Although the percentage of emotionally-charged words does not significantly vary from Block A to Block B (Figure 4), the previous data could suggest that a mixture of honorary/guest/gift authorship may also have taken place in Block B. Moreover, Block C shows a slight growth in the number of financial ACKs (Table 4), whereas instrumental and conceptual ACKs go down (Tables 5 and 6), and moral, editorial and unclassifiable ACKs remain more or less constant over time. Since the percentage of emotionally-charged words (Figure 4) and the mean number of ACKs/number of authors per RP (Figure 2) increase over time, and the number of authors decreases in comparison with Block B (see Méndez et al., 2014b), it can be clearly stated that honorary/guest/gift authorship is no longer characteristic of Block C. In this sense, and taking into account that $A J$ is the most experimentally-oriented journal of our sample, we can argue that due to the worldwide economic crisis which started in the USA in 2006 (Tully, 2006), less funding was devoted to research. This meant that fewer new projects were carried out and less new technology was developed, which implies that the traced instrumental ACKs mostly refer to already wellknown instruments, hence their lower number in Block $C$ in comparison to 
Block B. It may be then speculated that all the staff involved in the handling of those instruments, who perhaps qualified as authors in Block B (honorary authorship), are no longer considered as such in Block C.

MNRAS, a journal with the second highest impact factor and a publishing trend similar to ApJ, shows an increase in the average ACK-length (Figure 1) and in financial, instrumental and conceptual ACKs from Block A to Block C (Tables 4, 5 and 6), as well as in the number of named individuals, identified and non-identified referees (Tables 8 and 9). Conversely, moral, editorial and unclassifiable ACKs and unnamed individuals (Tables 7 and 8) decrease in the same time band. Likewise, there is a significant decline in the percentage of emotionally-charged words (Figure 4), whereas the number of authors rises outstandingly in Block C (see Méndez et al., 2014b). Similarly to ApJ, financial ACKs are the type of ACKs that increases the most in MNRAS. All these results could be attributed once more to the growing professionalization of science. Nevertheless, and although the mean number of ACKs/number of authors per RP (Figure 2) actually shows a slight decrease from Block $A$ to Block $C$, the absence of statistical significance in this indicator prevents us from clearly referring to the idea of honorary/guest/gift authorship.

In A\&A, a journal that publishes papers on theoretical, observational, and instrumental astronomy and astrophysics, we notice once more an increase in the average ACK-length (Figure 1) and in the number of financial and instrumental ACKs from Block A to Block C (Tables 4 and 5). The number of unnamed individuals and anonymous referees (Tables 8 and 9) also rises over time. Conversely, a decline from Block $A$ to Block $C$ is observed in the number of editorial and unclassifiable ACKs, named individuals and identified referees (Tables 7, 8 and 9), whereas conceptual and moral ACKs (Tables 6 and 7) remain practically stable. Similarly to MNRAS, we also find an outstanding decrease in the percentage of emotionally-charged words (Figure 4) and an increase in the number of authors in Block C (see Méndez et al., 2014b). All these data are in agreement with the already mentioned concept of professionalization of science. Moreover, the idea of honorary/guest/gift authorship has strongly to be dismissed in A\&A as the mean number of ACKs/number of authors per RP shows a clear, although non-statistically significant, increase from Block A to Block C (Figure 2). Unlike in MNRAS, the afore-mentioned fall of laudatory words in A\&A may be more clearly attributed to the growing use of a non-emotional and more impersonal register in science, reflecting thus the relationships among astrophysicists usually in force today. 
From a general standpoint, it can be stated that the very high frequency of ACKs found in astrophysics (Table 1) is consistent with previous studies dealing with ACKs in other 'hard' disciplines such as, for example, chemistry (Cronin et al., 2003, 2004), or medicine (Salager-Meyer et al., 2009, 2011), to name just a few. Of all the ACKs recorded (Table 3), it is the financial support, mainly public, that is most frequently acknowledged. This should come as no surprise since research in astrophysics is a clear example of Big Science which needs huge amounts of money and the participation of many companies and governments to be carried out (see "Introduction" section). Our results regarding the main sources of funding in astrophysics research would be then at variance with medical research which has been reported to be financed by the private sector (Salager-Meyer et al., 2009). The second most frequently acknowledged support is the technical/instrumental one, which is a clear reflection of the equipment-intensive nature of astrophysics research in the same line as other experimental research (Cronin \& Franks, 2006; Salager-Meyer et al., 2009). As for ACKs voiced at conceptual or peer interactive support, they have been considered foundational for identifying intellectual debts in fields such as astronomy (Verner, 1992, 1993, 1996), library and information science (Cronin et al., 1993) and computer science (Giles \& Councill, 2004) to the point that some researchers have even considered them to be at least as valuable as citations (Edge, 1979; McCain, 1991; Cronin et al., 1993; Cronin \& Weaver, 1995). In other more socialoriented fields such as humanities and social sciences (Cronin, 1995; Cronin et al., 2003; Díaz-Faes \& Bordóns, 2014), or in PhD dissertations and MA theses (Hyland, 2003), academic assistance has also been found to be important and may be probably linked to lower levels of co-authorship (Costas \& Leewen, 2012).

Diachronically speaking, the number of ACKs, their length and the mean number of words/number of ACKs per RP (Table 2) grow over time, although each type of ACK behaves differently. For example, financial, instrumental, and conceptual supports rise from Block A to Block C (Tables 4, 5 and 6), whereas moral, editorial and unclassified ACKs decline (Figure 3, Table 7). The numbers of emotionally-charged words (Table 10) and boosters, named individuals and identified referees (Tables 8 and 9) also show a decline from Block $A$ to Block $C$, as opposite to unnamed individuals and anonymous referees (Tables 8 and 9) which increase in the same time span. Once more, all these data can be interpreted in the light of the concept of Big Science.

If we establish a differentiation between the American publication context (A) and ApJ) and the European one (MNRAS and A\&A), we can see that RPs 
published in the American journals include more ACKs (Table 3), with a higher average-length and a higher mean number of ACKs/number of authors per RP (Table 1). Financial and instrumental ACKs predominate in the American context, whereas conceptual support prevails in the European one. Editorial ACKs are more prevalent in the European context, mainly in $A \& A$ where a vast majority of authors are non-native English speakers and may probably resort to editorial/ linguistic support. The number and variants of emotionally-charged words (Table 10) and boosters are lower in the ACKs published in the American journals. Since ACKs are usually longer in this context (Table 1), the percentage of this type of words is even lower (Figure 4). All these results may suggest that scientific professionalism is much more evident in the American context than in its European counterpart. The statistically significant decline noticed in the mean number of ACKs/number of authors per RP (Figure 2) in the American context may also suggest a growth in the referred scientific professionalism. However, the fact that emotionally-charged words increase in the American context, mainly led by AJ, as opposed to their decrease in the European context (Figure 4), must prevent us from drawing any clear and static picture. Likewise, the potential presence of honorary/guest/gift authorship, different for each journal, may even more tangle up the scenario.

\section{Conclusions}

In this paper, we have conducted a research study on the practice of ACKs, an important and standard feature of the scholarly communication process that reflects sub-author collaboration beyond co-authorship. We have analysed it in astrophysics, a field which has somehow been discursively left unaddressed but for a few exceptions.

The material presented here for the four principal scholarly journals in the field of astrophysics support the following general conclusions:

1. ACKs are an almost omnipresent section in astrophysics RPs.

2. The number of ACKs, their length, and the mean number of words per ACKs per RP grow over time.

3. Financial support is the most frequent type of ACKs, followed by technical/instrumental support. Public financial assistance predominates in contrast to other 'hard' sciences.

4. Financial, instrumental, and conceptual supports grow over time, whereas moral, editorial and unclassified assistance decline. 
5. The numbers of emotionally-charged words and boosters, named individuals and identified referees show a decline over time, in contrast with the number of unnamed individuals and anonymous referees.

6. All these data can be understood in the frame of growing scientific professionalism.

7. A detailed cross-journal analysis may suggest the occasional appearance of honorary/guest/gift authorship.

8. The RPs published in the American journals include more ACKs, with a higher average-length and a higher mean number of ACKs/number of authors per RP.

9. Financial and instrumental ACKs predominate in the American publication context, whereas conceptual and editorial ACKs prevail in the European one.

10. The percentage and variants of emotionally-charged words and boosters are lower in the ACKs published in the American journals.

Nevertheless, the complexity of the matters involved in such a heterogeneous discipline as astrophysics and the erratic changes noticed in some of the data analysed (for example, the slight increase over time of emotionally-charged words in the American context) limit the generalizability of these findings and cannot allow us to achieve very conclusive results. A larger sample would probably "unravel" the depicted situation and would support more robust claims on the behaviour of ACKs in the field of astrophysics.

\section{About the authors}

David I. Méndez holds a Ph. D. in Astrophysics from La Laguna University (Canary Islands, Spain). He is currently working as a tenured lecturer in the Department of Physics, Engineering Systems and Signal Theory at the Polytechnic University College of the University of Alicante (Spain), where he has been giving lectures, both in English and Spanish, of Fundamentals of Engineering Physics, Optics and Acoustics courses for almost fifteen years at graduate and postgraduate levels. He is a member of the Holography and Optical Processing research group of the University of Alicante. He has published numerous research articles on star formation and ionized gas in Wolf-Rayet Galaxies in the most prestigious Astrophysics journals such as The Astrophysical Journal, The Astronomical Journal, Astronomy \& Astrophysics, or Science. He has also published research articles on Photopolymer Optics in leading international journals 
such as Applied Optics, Optics Letters and Applied Physics Letters. Furthermore, he has published numerous research papers on Non-linear Oscillations in relevant journals such as International Journal of Nonlinear Sciences and Numerical Simulation, Journal of Sound and Vibration or Computers and Mathematics with Applications among others. Recently he has expanded his research to include Information Science and Linguistics matters in English with publications in international journals such as Scientometrics, Advances in Language and Literature, Revista Canaria de Estudios Ingleses, or International Journal of Applied Linguistics \& English Literature.

M. Ángeles Alcaraz holds a B.A. and a M.A. in English Studies and a Ph.D. in Linguistics from the University of Alicante (Spain). Since 2003 she is currently working at the University of Alicante as a tenured lecturer in the Department of English Studies, where she is giving lectures of English for Tourism at both graduate and postgraduate levels. Till two years ago she also taught Medical English at a postgraduate level. She is the author of numerous research articles, conference papers and other publications on the linguistic and pragmatico-rhetorical analysis of English-, French- and Spanish-written medical discourse. She has published in well-known international journals such as English for Specific Purposes, Fachsprache, Ibérica, Journal of Pragmatics, Journal of the American Society for Information Science and Technology, Lebende Sprachen, Scientometrics, Spanish in Context, The ESPecialist, and in edited books (eg. Lengua Española y Traducción, Intercultural Aspects of Specialized Communication, Elsevier Encyclopedia of Language and Linguistics, Advances in Medical Discourse Analysis: Oral and written contexts, Language and Discipline Perspectives on Academic Discourse, etc.). In 2004 she was awarded the Horowitz Prize for her diachronic and cross-linguistic and cultural research on academic conflict in the field of medicine. Recently she is also doing research in the field of Astrophysics written in English from both linguistic and scientometric standpoints and has published in Scientometrics, Advances in Language and Literature, Revista Canaria de Estudios Ingleses, or International Journal of Applied Linguistics \& English Literature. She is a member of IPA (Inglés para Fines Profesionales y Académicos) from the University of Alicante and of the Multilingual and Multidisciplinary Research Group on Scientific Discourse Analysis from the University of Los Andes, Mérida (Venezuela). 


\section{LFE Article history}

Paper received: 15th March 2015

Paper received in revised form and accepted for publication: 8th June 2015

\section{References}

Bazerman, C. (1994). Constructing experience. Carbondale, IL: Southern Illinois University Press.

Bazerman, C. (2000). Shaping written knowledge: The Genre and activity of the experimental article in science. WAC Clearinghouse Landmark Publications in Writing Studies. <http://wac.colostate.edu/books/bazerman_shaping> [16/07/2015].

Beer, J. J., \& Lewis, W. D. (1963). Aspects of the professionalization of Science. Daedalus, 92(4), 764-784.

Butler Burton, W. (2007). Some statistics regarding the astrophysical Journal as published between 1990 and 2006, including comparisons with sister journals. In A. Heck \& L. Houziaux (Eds.), Future professional communication in astronomy (31-59). Bruxelles: Mémoires de l'Académie Royale de Belgique.

Claxton, L. D. (2005). Scientific authorship. Part 2. History, recurring issues, practices and guidelines. Mutation Research, 589, 31-45. doi:10.1016/j.mrrev.2004.07.002.

Connor, U. (2004). Intercultural rhetoric research: Beyond texts. Journal of English for Academic Purposes. Special Issue on Contrastive Rhetoric in EAP, 3(4), 291-305. doi:10.1016/j.jeap.2004.07.003.

Costas, R., \& van Leeuwen, T. N. (2012). Approaching the 'Reward Triangle': General analysis of the presence of funding acknowledgments and 'peer interactive communication' in scientific publications. Journal of the Association for Information Science and Technology, 63(8), 1647-1661. doi: 10.1002/asi.22692.

Cronin, B. (1995). The Scholar's Courtesy. The Role of acknowledgments in the primary communication process. London: Taylor Graham.

Cronin, B., \& Weaver, S. (1995). The praxis of acknowledgment: From bibliometrics to influmetrics. Revista Española de Documentación Científica, 18(2), 172-177. doi:10.3989/redc.1995.v18.i2.654.

Cronin, B., \& Franks, S. (2006). Trading cultures: Resources mobilization and service rendering in the life sciences as revealed in the journal articles' paratext. Journal of the American Society for Information Science and Technology, 57(14), 1909-1918.

Cronin, B., McKenzie, G., \& Rubio, L. (1993). The norms of acknowledgments in four humanities and social sciences disciplines. Journal of Documentation, 49(1), 29-43. 
Cronin, B., Shaw, D., \& La Barre, K. (2003). A cast of thousands: Coauthorship and subauthorship collaboration in the $20^{\text {th }}$ century as manifested in the scholarly literature of Psychology and Philosophy. Journal of the American Society for Information Science and Technology, 54(9), 855-871. doi: 10.1002/asi.10278.

Cronin, B., Shaw, D., \& La Barre, K. (2004). Visible, less visible, and invisible work: Patterns of collaboration in 20th century chemistry. Journal of the American Society for Information Science and Technology, 55(2), 160-168. doi:10.1002/asi.10353.

Curry, M. J., \& Lillis, T. (2004). Multilingual scholars and the imperative to publish in English: Negotiating interests, demands and rewards. TESOL Quarterly, 38(4), 663-688. doi: $10.2307 / 3588284$.

De Faoite, D. (2010). Guest authorship: How common is it and what are the reasons behind it? The Write Stuff, 19(1), 32-34.

De Solla Price, D. J. (1963). Little Science, Big Science. New York: Columbia University Press.

Díaz-Faes, A. A., \& Bordóns, M. (2014). Acknowledgments in scientific publications: Presence in Spanish science and text patterns across disciplines. Journal of the Association for Information Science and Technology, 65(9), 1834-1849. doi: 10.1002/asi.23081.

Edge, D. (1979). Quantitative measures of communication in science. History of Science, 19, 102-134.

Galison, P. (1992). Big Science: The growth of large-scale research. Standford, CA: Standford University Press.

Gasparyan, A. Y., Ayvazyan, L., \& Kitas, G. D. (2013). Authorship problems in scholarly journals: Considerations for authors, peer reviewers and editors. Rheumatology International, 33(2), 277-284. doi: 10.1007/ s00296-012-2582-2.

Gentil-Beccot, A., Mele, S., \& Brooks, T. C. (2009). Citing and reading behaviours in highenergy physics. How a community stopped worrying about journals and learned to love repositories. <http://arxiv.org/ftp/arxiv/papers/0906/0906.5418.pdf > [16/07/2015].

Gesuato, S. (2004). Acknowledgments in Ph.D dissertation: The complexity of thanking. In T. Torsello, C. Busà, M. Grazia \& S. Gesuato (Eds.), Lingua Inglese e mediazione linguistica. Ricerca e didattica con supporto telematico (273-318). Padova: Unipress.

Giannoni, D. S. (2006). Book acknowledgments across disciplines and texts. In K. Hyland \& M. Bondi (Eds.), Academic discourse across disciplines (151-175). Bern: Peter Lang.

Giles, C. L., \& Councill, I. G. (2004). Who gets acknowledged: Measuring scientific contributions through automatic acknowledgment indexing. Proceedings of the National Academy of Science, 101(51), 17599-17604. doi: 10.1073/pnas.0407743101.

Gómez, I., Sancho, R., Bordóns, M., \& Fernández, M. T. (2006). La I+D en España a través de sus publicaciones y patentes. In J. Sebastián \& E. Muñoz (Eds.), Radiografía de la Investigación Pública (275-302). Madrid: Biblioteca Nueva. 
Gordon, M. D. (1980). A critical reassessment of inferred relations between multiple authorship, scientific collaboration, the production of papers and their acceptance for publication. Scientometrics, 2(3), 193-201. doi: 10.1007/BF02016697.

Hare, D. (2001). Giving credit where credit is due - Authorship versus acknowledgment. The Canadian Veterinary Journal, 42, 249-250.

Hyland, K. (1998). Persuasion and context: The pragmatics of academic metadiscourse. Journal of Pragmatics, 30, 437-455. doi: 10.1016/S0378-2166(98)00009-5.

Hyland, K. (2003). Dissertation acknowledgments: The anatomy of a Cinderella genre. Written Communication, 20(3), 242-68. doi: 10.1177/0741088303257276.

Hyland, K. (2004). Graduates' gratitude: The generic structure of dissertation acknowledgments. English for Specific Purposes, 23(3), 303-224. doi:10.1016/S08894906(03)00051-6.

Kassirer, J., \& Angell, M. (1991). On authorship and acknowledgment. The New England Journal of Medicine, 325(21), 1510-1512.

Khabsa, M., Koppman, S., \& Giles, S. L. (2012). Towards building and analyzing a social network of acknowledgments in scientific and academic documents. In S. J. Yang, A. M. Greenberg \& M. Endsley (Eds.). Proceedings of the 5th international conference on social computing, behavioral-cultural modeling and prediction. Lecture notes in computer science: Authors' instructions 7227 (pp. 357-364). Berlin/Heidelberg: Springer-Verlag.

McCain, K. (1991). Communication, competition and secrecy: The production and dissemination of research-related information on genetics. Science, Technologies and Human Values, 16(4), 491-516.

Méndez, D. I., Alcaraz, M. Á., \& Salager-Meyer, F (2014a). Titles in English-medium Astrophysics research articles. Scientometrics, 98(3), 2331-2351. doi: 10.1007/s11192-0131174-6.

Méndez, D. I.; Alcaraz, M Á., \& Salager-Meyer, F. (2014b). Evaluating authorship variation patterns in English-medium Astrophysics research papers: An across journal and diachronic study (1998-2012). Revista Canaria de Estudios Ingleses (RCEI), 69, 49-61.

Newman, M. E. J. (2004). Coauthorship networks and patterns of scientific collaboration. Retrieved from Proceedings of the National Academy of Sciences of the United States of America 101, Suppl 1.

Patel, N. (1973). Collaboration in the professional growth of American sociology. Social Science Information, 12(6), 77-92.

Pedersen, O. (2009). Early physics and astronomy: A historical introduction. Cambridge, UK: Cambridge University Press.

Rennie, D., Yank, V., \& Emmanuel, L. (1997). When authorship fails: A proposal to make contributions accountable. JAMA, 278(7), 579-585.

Salager Meyer, F., Alcaraz Ariza, M. Á., \& M. Pabón Berbesí (2009). Backstage solidarity in Spanish- and English-written medical research papers: Publication context and the 
acknowledgment paratext. Journal of the American Society for Information Science and Technology, 60(2), 307-317. doi: 10.1002/asi.20981.

Salager-Meyer, F., Alcaraz-Ariza, M. Á., Briceno, \& M. L. \& Jabbour, G. (2011). Scholarly gratitude in five geographical contexts: A diachronic and cross-generic approach of the acknowledgment paratext in medical discourse (1950-2010). Scientometrics, 86(3), 763784. doi:10.1007/s11192-010-0329-y.

Shapin, S. (1995). A social history of truth: Civility and science in seventeenth century England. Chicago: Chicago University Press.

Slatcher, R. B., \& Pennebaker, J. W. (2006). How do I love thee? Let me count the words. Psychological Science, 17(8), 660-664. doi: 10.1111/j.1467-9280.2006.01762.x.

Suls, J., \& Fletcher, B. (1983). Social comparison in the social and physical sciences: An archival study. Journal of Personality and Social Psychology, 44(3), 575-580. doi: 10.1037/00223514.44.3.575.

Swales, J. (2004). Research genres: Exploration and applications. Cambridge, UK: Cambridge University Press.

Tarone, E., Dwyer, S., Gillette, S., \& Icke, V. (1998). On the use of passive in two astrophysics journal papers. English for Specific Purposes, 1(2), 123-139. doi: 10.1016/S08894906(97)00032-X.

Tully, S. (2006). Welcome to the dead zone. <http://money.cnn.com/2006/ 05/03/news/economy/realestateguide_fortune/> [16/07/2015].

Verner, D. A. (1992). Astronomy Acknowledgment Index 1991. ESO Messenger, 67, 61-62.

Verner, D. A. (1993). Astronomy Acknowledgment Index 1992. ESO Messenger, 71, 59.

Verner, D. A. (1996). List of Astronomy Acknowledgment Index 1995-1996. <http://www.pa. uky.edu/ verner/aai.html> [16/07/2015].

Vinther S., \& Rosenberg, J. (2012). Authorship trends over the past fifty years in the Journal of the Danish Medical Association (Danish: Ugeskrift for Læger). Danish Medical Journal, 59(3), A4390.

Weingberg, A. M. (1961). Impact of large-scale science on the United States. Science, 134, 161 164. doi: 10.1126/science.134.3473.161.

Weinberg, A. M. (1968). Reflections on Big Science. Cambridge, MASS: MIT Press. 


\section{Appendix}

Emotionally-charged words

\begin{tabular}{|c|c|c|c|c|c|}
\hline $\begin{array}{l}\text { Emotionally-charged } \\
\text { words }\end{array}$ & AJ & ApJ & MNRAS & A\&A & TOTAL \\
\hline careful & $0-1-3$ & $1-1-0$ & $2-1-2$ & $5-2-0$ & 18 \\
\hline carefully & $0-0-0$ & $0-0-0$ & $0-1-0$ & $0-1-0$ & 2 \\
\hline cheerfully & $0-1-0$ & $0-0-0$ & $0-0-0$ & $0-0-0$ & 1 \\
\hline constructive & $1-2-0$ & $1-2-1$ & $1-1-1$ & $1-3-2$ & 16 \\
\hline deeply & $0-0-0$ & $0-0-0$ & $0-0-0$ & $1-0-0$ & 1 \\
\hline encouraging & $0-0-0$ & $0-0-0$ & $0-0-0$ & $0-1-0$ & 1 \\
\hline enlightening & $1-0-0$ & $0-0-0$ & $0-0-1$ & $0-0-0$ & 2 \\
\hline (e)special & $1-0-0$ & $0-0-1$ & $0-0-1$ & $0-0-0$ & 8 \\
\hline (e)specially & $0-0-0$ & $1-0-2$ & $1-0-1$ & $2-1-0$ & 8 \\
\hline excellent & $1-0-2$ & $2-0-1$ & $1-0-0$ & $0-0-2$ & 9 \\
\hline extremely & $0-0-0$ & $0-0-0$ & $0-0-0$ & $0-1-0$ & 1 \\
\hline fruitful & $0-0-0$ & $0-0-0$ & $0-0-1$ & $2-3-1$ & 7 \\
\hline generous & $0-3-1$ & $1-0-0$ & $0-2-0$ & $0-0-0$ & 7 \\
\hline generously & $0-0-0$ & $1-0-1$ & $0-0-0$ & $0-0-0$ & 2 \\
\hline grateful & $5-8-14$ & $8-6-4$ & $7-9-7$ & $11-6-4$ & 89 \\
\hline gratefully & $2-2-1$ & $1-3-0$ & $3-1-1$ & $4-1-0$ & 19 \\
\hline gratitude & $0-3-0$ & $0-0-0$ & $0-0-2$ & $2-0-0$ & 7 \\
\hline great & $0-0-0$ & $0-0-1$ & $0-0-1$ & $1-0-1$ & 4 \\
\hline greatly & $1-2-3$ & $2-0-1$ & $2-0-1$ & $1-0-0$ & 13 \\
\hline illuminating & $0-0-0$ & $1-0-0$ & $0-0-0$ & $0-0-1$ & 2 \\
\hline interesting & $0-0-0$ & $2-1-0$ & $2-2-0$ & $0-0-0$ & 7 \\
\hline insightful & $0-1-0$ & $0-1-2$ & $0-1-0$ & $0-0-0$ & 5 \\
\hline invaluable & $2-0-0$ & $0-0-0$ & $1-1-0$ & $2-1-1$ & 8 \\
\hline kind & $0-1-0$ & $0-0-0$ & $1-2-0$ & $3-0-0$ & 7 \\
\hline kindly & $2-0-1$ & $1-0-0$ & $0-1-0$ & $1-2-1$ & 9 \\
\hline pleasure & $0-1-1$ & $1-1-0$ & $3-0-1$ & $0-0-0$ & 8 \\
\hline positive & $0-0-1$ & $0-0-0$ & $0-0-0$ & $0-0-0$ & 1 \\
\hline significant & $1-0-0$ & $1-0-1$ & $0-0-0$ & $0-0-0$ & 3 \\
\hline significantly & $0-0-0$ & $0-0-0$ & $0-1-1$ & $1-0-0$ & 3 \\
\hline sincere & $1-0-1$ & $0-0-0$ & $0-0-0$ & $1-0-0$ & 3 \\
\hline stimulating & $0-0-0$ & $0-2-0$ & $1-2-0$ & $0-1-0$ & 6 \\
\hline thankful & $0-0-0$ & $0-0-0$ & $0-1-0$ & $1-0-2$ & 4 \\
\hline thoughtful & $0-1-0$ & $1-0-0$ & $0-0-1$ & $0-0-0$ & 3 \\
\hline useful & 3-5-8 & $6-8-6$ & $3-10-6$ & $5-15-5$ & 80 \\
\hline valuable & $2-3-0$ & $2-4-0$ & $4-1-3$ & $1-2-4$ & 26 \\
\hline warmly & $0-0-0$ & $0-0-0$ & $0-1-2$ & $0-0-1$ & 4 \\
\hline
\end{tabular}




\begin{tabular}{l|l|l|l|l|l}
\hline Boosters & AJ & ApJ & MNRAS & A\&A & TOTAL \\
\hline a number of & $0-0-0$ & $0-0-0$ & $0-0-1$ & $0-0-0$ & 1 \\
\hline many & $3-0-1$ & $2-3-1$ & $2-4-4$ & $1-3-2$ & 26 \\
\hline numerous & $0-0-0$ & $0-1-0$ & $0-1-2$ & $1-1-0$ & 6 \\
\hline plenty & $0-0-0$ & $0-0-0$ & $0-1-0$ & $0-0-0$ & 1 \\
\hline several & $0-0-1$ & $0-1-0$ & $1-0-0$ & $0-0-0$ & 3 \\
\hline very & $1-2-4$ & $0-1-1$ & $0-1-2$ & $2-4-1$ & 19 \\
\cline { 2 - 6 }
\end{tabular}

NOTE: Each number in each column corresponds to a period of time. For example, in $A$ J, the first number in "careful" refers to Block $A$ (0 occurrence), the second number to Block B (one occurrence), and the third number to Block C (three occurrences). 